\title{
Assessment of Scientific Reasoning Skills Learned from Lab Modules with Varying Degrees of Inquiry
}

\author{
Aaron Coleman', Sahil Khan, and Goran Bozinovic \\ ${ }^{1}$ University of California San Diego, Division of Biological Sciences, 9500 Gilman Drive, La \\ Jolla CA 92093 USA \\ (abcoleman@ucsd.edu)
}

\section{Extended Abstract}

In addition to learning the facts and concepts of biology, we hope that our students are learning how science works as a process. This includes the reasoning skills required to form hypotheses, analyze data, and design experiments to test a given question. These skills are best learned in laboratory classes, where students can engage in the scientific process. Recent calls for reform in biology undergraduate education have urged a change to more inquiry-based laboratory classes. It is logically assumed that students learn scientific reasoning better from inquiry-based classes, however there are few controlled studies that have examined this. Furthermore, the degree of inquiry used in published lab modules ranges considerably. In guided inquiry labs, the instructor provides the question and experimental methods, whereas in open inquiry labs the question and methods are determined by the students, although both are considered inquiry-based. The assessment of most published inquiry lab modules has been uncontrolled or has made comparisons to labs with no inquiry. We have designed an assessment to measure scientific reasoning skills, and administered it to students before and after completion of our biochemistry lab course. Two versions of the main course module were rotated through the class in different terms, a low-inquiry version where instructor provided the experimental question and design, and a high-inquiry version where the students determined the hypothesis/question and designed the experiment.

The scientific reasoning skills assessment was able to measure pre to post-class gains across multiple classes taught by different instructors. Three of 5 classes assessed showed a statistically significant increase for the average score. The two high-inquiry classes showed statistically significant increases in student learning of scientific reasoning skills, with a small effect size as measured by Cohen's $d$. Two of the three low-inquiry classes showed no improvement or small, non-significant improvement in average score. However, the third low inquiry-class showed strong, significant improvement with a moderate effect size.

Keywords: science process skills, inquiry-based labs, scientific reasoning, assessment

Link to Original Poster File: https://doi.org/10.37590/able.v41.poster63

\section{Mission, Review Process \& Disclaimer}

The Association for Biology Laboratory Education (ABLE) was founded in 1979 to promote information exchange among university and college educators actively concerned with teaching biology in a laboratory setting. The focus of ABLE is to improve the undergraduate biology laboratory experience by promoting the development and dissemination of interesting, innovative, and reliable laboratory exercises. For more information about ABLE, please visit

http://www.ableweb.org/.

Advances in Biology Laboratory Education is the peer-reviewed publication of the conference of the Association for Biology Laboratory Education. Published articles and extended abstracts are evaluated and selected by a committee prior to presentation at the conference, peer-reviewed by participants at the conference, and edited by members of the ABLE Editorial Board. Published abstracts are evaluated and selected by a committee prior to presentation at the conference. 


\section{Citing This Article}

Coleman A, Khan S, and Bozinovic G. 2020. Assessment of scientific reasoning skills learned from lab modules with varying degrees of inquiry. Article 63. In: McMahon K, editor. Advances in biology laboratory education. Volume 41. Publication of the 41st Conference of the Association for Biology Laboratory Education (ABLE). hittps://doi.0rg/10.37590 able.v41.abs63

Compilation (C) 2020 by the Association for Biology Laboratory Education, ISBN 1-890444-17-0. All rights reserved. Nopart of this publication may be reproduced, stored in a retrieval system, or transmitted, in any form or by any means, electronic, mechanical, photocopying, recording, or otherwise, without the prior written permission of the copyright owner.

ABLE strongly encourages individuals to use the exercises in this proceedings volume in their teaching program. If this exercise is used solely at one's own institution with no intent for profit, it is excluded from the preceding copyright restriction, unless otherwise noted on the copyright notice of the individual chapter in this volume. Proper credit to this publication must be included in your laboratory outline for each use; a sample citation is given above. 